"This is the peer reviewed version of the following article: Towards a non-ethics-based consensual public policy on abortion, which has been published in final form at http://dx.doi.org/10.1002/hpm.2320. This article may be used for non-commercial purposes in accordance with Wiley Terms and Conditions for Use of Self-Archived Versions." 


\section{Towards a non-ethics-based consensual public policy on abortion}

While I do recognize that political norms are usually compatible with ethical imperatives, I also hold that political and ethical rules occasionally follow different purposes and may sometimes come into conflict. In capital punishment, war, political intelligence and state-regulated overpopulation measures, the individual's life, privacy and desire to reproduce (which are regarded as various forms of ethical good by numerous ethical theories) clash with the state's interest, and certain policies are forced to set (ethical) good and evil to the side. The conflict between ethics and politics cannot be discarded a priori, even among ethical approaches not centered on the individual; the controversial relationship between certain religious communitarian ethics and the modern secular states may well serve as an illustration (Alvargonzález 2013a).

Furthermore, for better or worse, politics and legislation do not have a say in all aspects of human behavior, even when certain behaviors could be labeled as unethical. For instance, tobacco consumption and alcohol abuse have proven harmful to the individual's health and may adversely affect his/her family; nevertheless, they are legally permissible in most countries. As is well known, Prohibition, mandated under the Eighteenth Amendment of the Constitution of the United States and considered to be progressive at the time, increased criminal activity surrounding alcohol production and distribution, and was eventually repealed. As a motto of political prudence states, sometimes "the remedy may be worse than the disease".

Without detracting from the importance of the ethical debates on induced abortion, it is worth recognizing that the numerous conceptions concerning the status of the human 
embryo and fetus and the diversity of ethical frameworks make impossible to reach a universal consensus on the ethical discussion of abortion.

Ethical debates between pro-choice and pro-life supporters have frequently fed the political agenda on abortion: liberal parties usually defend a wide range of pro-choice legislation while conservative parties push for more restrictive laws and implementations. In certain countries, convergence among the main political parties on salient basic policies has led them to wave the issue of abortion as one of their banners in an effort to differentiate themselves from their rivals.

Consequently, when policies on abortion are grounded on ethical principles, they tend to be inherently controversial. On one hand, there is a wide variation in laws from one country to another and, on the other, the policies of any given country risk fluctuating as power changes hands from one party to another. Moreover, abortion policies that are based on ethical ideas may also be a source of social malaise; if the law remains unchanged despite political fluctuations, it is often at the expense of a significant portion of society, one which feels that certain ethical principles (either the autonomy of women or the life of healthy human embryos and fetuses) are not being fully respected. Simon C. May has proposed certain persuasive arguments against the project of pursuing an ethical principled compromise between the pro-choice and the pro-life camps (May 2005).

Infanticide, abortion and contraception constitute issues of public concern which cannot be put off until the ethical debate is definitely settled since, as happens with many philosophical problems, the ethical discussion itself may have no solution. However, this by no means implies skepticism as regards the ethics of abortion. I have discussed the different ethical theories on abortion and have defended my own stance elsewhere 
(Alvargonzález 2009), although such discussion falls outside of the scope of this brief commentary.

As stated, ethics and politics may serve different purposes and, consequently, even if an ethical consensus on abortion were reached, the discussion about the best policy to follow would remain a different, unresolved issue altogether.

\section{UNINTENDED PREGNANCIES AND ABORTIONS}

According to a recent estimate, $41 \%$ of the 208 million pregnancies that took place worldwide in 2008 were unintended, and half of those unintended pregnancies ended in abortion (Singh et al 2010). Although some women who are seeking to become pregnant change their minds afterwards (due to health problems and other reasons), estimates for the United States suggest that less than 5\% of abortions occur when the pregnancy is intentional (Finer and Henshaw 2001).

In 2010, Singh and others listed the most frequent causes of unintended pregnancies. The general factors underlying unintended pregnancies are "poverty [...], stigma against unmarried mothers, a cultural preference for sons, competing demands on women's time $[\ldots]$, completion of family size, disagreement between spouses about family size, lack of support from one's partner [...], and poor access to family planning services" (Singh et al 2010, 246). Proximate causes include non-use or discontinuation of contraception due to problems with methods or supplies, fear of adverse side effects, partner opposition and problems with accessing appropriate services. Other causes are a poor understanding of the risks of pregnancy and unexpected changes in life circumstances (Singh et al 2010, 246). The costs of unintended pregnancies are high: Trussell estimates that, in the United States alone, they amounted to about US\$ 5 billion in 2002 (Trussell 2006). 


\section{BASIS FOR A UNIVERSALLY CONSENSUAL ABORTION POLICY: REDUCING ABORTION RATES}

The lack of an ethical consensus on abortion does not entail the impossibility of reaching an agreement on the best policies to be implemented. Political concurrence can be rooted on the fact that even the staunchest pro-choice advocates recognize that abortion is not the best method to be used by women seeking to limit or space out childbearing. Contraception is always seen as a better choice than abortion among both pro-choice and pro-life supporters. As regards methods of birth control, it is universally accepted that contraception is preferable to abortion, just as abortion is preferable to infanticide (Giubilini and Minerva 2011). There is also a reliable consensus that abortion is worse the later and less safely it is performed.

High abortion rates are nowhere touted as a source of pride, except when they are correlative to a reduction of high infanticide rates since, as stated, infanticide is always regarded as the worst option.

Furthermore, it is widely recognized that contraceptive use implies substantial, direct medical cost savings: estimates for the United States in 2002 put the figure at US\$ 19 billion (Trussell 2006).

Consequently, the aims of diminishing abortion rates, lowering the gestational age at which abortions occur and making remaining abortions safer can be taken on by any state as objectives for a enduring abortion policy.

Any attempt to eliminate abortion fully can be seen as idealistic and utopian. Since it is impossible to control each and every circumstance in life, a certain number of abortions will always exist and will be impossible to prevent (Bankole et al 1998). Abortion 
policies should then accept certain limitations and be satisfied with a progressive reduction in abortion rates, a lowering of gestational abortion ages and an amelioration of abortion practices. Indeed, these limitations are due to certain inherent features of today's world, such as the increase of international mobility and the advent of easy abortion technologies.

Following the widespread triumph of consumer capitalism, tight border controls resembling those carried out in the former Soviet Union can no longer be considered a viable policy to curb people's movements. Also, abortion legislation usually shows a wide variation between neighboring states and has a direct influence on the number and quality of abortion providers. Accordingly, since a person's international mobility is a non-negotiable issue, different levels of restriction among nearby states induce the uncontrollable cross-state travel of women seeking abortion (Blank and George 1996; Kreimer 1992).

Another limitation any realistic abortion policy must face is the inability to control early abortions in the wake of the wide accessibility of certain easy abortion technologies. As in Prohibition, the complete ban of these new technologies and the subsequent creation of an underground abortion economy do not seem to be a prudent political alternative. Accordingly, it is a matter of fact that modern states cannot exercise effective control over abortions during the first trimester of gestation.

Consequently, states have to assume that the aim of completely eliminating abortion is idealistic, while the aims of diminishing abortion rates, lowering the gestational age at which abortion takes place and reducing morbidity and mortality from abortion should be the main realistic aspirations of any abortion policy. 
Restrictive abortion laws are usually defined as those outlawing abortion on request or on socioeconomic grounds. Strange as it may seem, there is no correlation between restrictive abortion laws and low abortion rates. A study on the impact of state-level restrictions on abortion in the United States concludes that restrictive policies do not have any impact on abortion rates and do not have the effects sought by pro-life supporters (Meier 1996). Rather, to the contrary, Gilda Sedgh and others have found that, in 2008, abortion rates were lower among women living under liberal abortion laws (Sedg 2012). However, as the authors themselves recognize, this correlation could be a consequence of the fact that, in regions dominated by liberal laws, women have better access to effective modern contraception (Marston and Cleland 2003).

According to overall estimates, in 200821.6 million women underwent unsafe abortions, mostly (18.5 million) in developing countries (WHO 2011). If, as stated, the main political aim is to reduce the abortion rate, it should be acknowledged that abortions will still be performed as this aim is being met and, in the long term, abortions will never be completely avoided. Accordingly, good public health policies must prevent women's morbidity and mortality due to such abortions since women have the right to not fall ill and to not die as a result of an abortion and should receive the appropriate care when required.

Non-restrictive abortion laws do not, on their own, ensure the safety of abortions, since safety also depends on abortion providers' training and the appropriate provision of health services. Nonetheless, there is evidence that "unsafe abortion procedures, untrained abortion providers, restrictive abortion laws and high mortality and morbidity from abortion tend to occur in one and the same countries" (Berer 2000, 580). The 
safety of abortions is not only affected by existing laws but also by the way the laws are implemented and enforced (Rahman et al 1998).This association is hardly surprising, since restrictive laws and a restrictive interpretation of the law act as a barrier to professional abortion services and may induce an uncontrolled underground abortion economy. Consequently, a policy on abortion centered on women's health seems incompatible with restrictive legislation and the restrictive enforcement of existing laws. Certain pro-life supporters contend that restrictive legislation on abortion has the advantage of making explicit the state's commitment to the life of the unborn and to the social and moral condemnation of abortion. In their eyes, restrictive laws contribute to creating a general opinion against abortion and inducing virtue ethics among citizens. Brody argues that many women seeking to limit or space out childbearing reject abortion because of its illegality, although they would probably opt for it if it were it legal (Brody 1971). I have not found any empirical evidence for this assumption, although there is a reasonable suspicion that prosecution could be counterproductive since an attempt to excel can actually prevent good practice: restrictive laws could give rise to "abortion tourism" among the rich and risky abortions among the poor.

In any case, as stated, restrictive abortion laws do not imply lower abortion rates and do correlate with higher women's morbidity and mortality from abortion. Even the most vociferous pro-life advocate must understand that, in the political sphere, the dubious and controversial advantages of state exemplarism and social and moral condemnation are not enough to outweigh the serious disadvantage of increasing women's morbidity and mortality from abortion. As the benefits are dubious and disadvantages clearly established, any state assuming the political aim of discouraging women from abortion (due to the ethical repulsion of democratic majorities or simply as a dubious instrument 
to reduce abortion rates), would do better implementing more productive prevention policies through education and publicity.

\section{UNMET NEED FOR CONTRACEPTION IS ONE OF THE MAIN CAUSES OF UNINTENDED PREGNANCIES. THE TRADEOFF BETWEEN ABORTION AND EFFECTIVE CONTRACEPTION}

A fertile, sexually active woman is said to have an unmet need for contraception if she does not want to have a child in the next two years and is not using any contraception procedure. Women using traditional contraception methods, which have a high failure rate, are also categorized as having an unmet need for effective contraception.

Credible studies have shown that appropriate access to effective contraception by groups at risk for unintended pregnancy contributes to lower abortion rates. According to Singh and others, "In 2008, modern contraceptive use prevented 188 million unintended pregnancies [...]. If the 215 million women with unmet need used modern family planning methods, current unintended pregnancies would drop by $71 \%$, from 75 million to 22 million per year [...]. Eliminating 53 million more unintended pregnancies per year would result in about 22 million fewer unplanned births, 25 million fewer induced abortions, and 7 million fewer miscarriages" (Singh et al 2009, 19).

Bongaarts and Westoff have shown that there is a tradeoff between abortion and contraception. Consequently, abortion rates can be reduced by raising the prevalence and effectiveness of contraception. The effect of that tradeoff varies among societies depending on the abortion probability: the higher the abortion probability, the greater the tradeoff effect due to improved contraception. They have also proposed a theoretical perfect contraceptive population model according to which if all fecund women who do 
not intend to become pregnant practiced $100 \%$ effective contraception, the total abortion rate would reduce to nearly zero (Boongaarts and Westoff 2000).

Consistent with the foregoing, comprehensive sex education programs, good contraceptive services and accessible emergency contraception are associated with countries where contraceptive prevalence is high and abortion rates are low, such as Germany and Belgium. Yet, even in those countries, the effectiveness of preventing unwanted pregnancy clashes with the problem arising from the mismatch between contraceptive needs and the methods used (Bajos et al 2003).

Consequently, good government policies should indentify the groups of women at greater risk of unintended pregnancies and unmet need for contraception, and should implement programs to provide modern contraceptive services when needed (Forrest 1994; Finer and Zolna 2011). School and community-based education on human reproduction and contraception may also contribute to the decline of unintended pregnancies (Vincent et al 1987).

Even apart from any ethical or political consideration, a personal choice entails purely egocentric and practical reasons to prefer contraception over abortion: lower costs and risks, and the lack of encroachment on one's health. Ultimately, beyond the ethical controversy and political advisability, these are the universally valid arguments to be employed when dissuading women from considering abortion to be a sound method of birth control. Due to their recent history, in certain countries such as Greece, the former Yugoslavia and the former Soviet Union, there is still a "culture of abortion as a contraceptive method" (Berer 2000). In those cases, efforts in education and awarenessraising should be made to change that irrational mindset and lower their high abortion rates. 
Ethical reasons will always come into play in the personal decision to abort a healthy implanted human embryo or fetus, and the ethical argumentation involved will be very different from that of the practical political approach set forth herein. Assuming the validity of the present proposal, anti-abortion supporters should resign themselves to living under non-restrictive legislation; however, as the ethical debate on abortion is still open, women undergoing abortions and abortion providers and entrepreneurs will not be able to escape the rebuke of a substantial portion of society and even of the state, in the event that such state has explicitly made an ethical condemnation of abortion.

\section{STRENGTH AND WEAKNESS OF THE PRESENT PROPOSAL}

While the idea of "humankind's general progress" has been widely criticized in contemporary philosophy, a limited concept of progress can still be used in particular technical and technological contexts (Alvargonzález 2013b). Procedures seeking to limit or space out childbearing are one of such contexts in which it makes sense to speak about progress: setting ethics to the side, infanticide is a worse technique than abortion, abortion is a worse technique than contraception and abortion is worse the later and less safely it is performed. Any policy regarding those issues can firmly rest on those bases. The main weakness of the present proposal concerns the evaluation of the practical consequences of restrictive legislation on abortion. This paper has made use of certain evidence showing that restrictive legislation does not contribute to lowering abortion rates and is associated with unsafe abortions. This evidence is the main argument to dissuade anti-abortion supporters from promoting such noxious legislation. The foundations of the policy outlined herein would greatly benefit from future research on the influence of restrictive legislation and implementations on abortion rates and safety. 
The international consensual policy of abortion set forth herein is possible and recommendable. It removes the fraught ethical debate from the political agenda, encourages a coordinated international policy to end abortion tourism and clarifies what is politically possible. Utopian objectives cannot be the excuse for wrong decisions and inaction and, consequently, they should be replaced by politically achievable aims: lowering abortion rates as much as possible, diminishing the gestational age of abortions and making the remaining, unavoidable abortions safer. Educating the population so it can make a reasoned judgment of the ethical discussion is a separate matter.

\section{ACKNOWLEDGEMENTS}

I wish to thank Brendan Burke for his help in improving the English and the style of the text. 


\section{REFERENCES}

Alvargonzález D. 2009. La clonación, la anticoncepción y el aborto en la sociedad biotecnológica. Pentalfa: Oviedo.

Alvargonzález D. 2013a. Alzheimer's disease and the conflict between ethics, morality and politics, J Alzheimers Dis Parkinsonism S10 004, special issue Neurodegenerative disorders. DOI: 10.4172/2161-0460.S10-004.

Alvargonzález D. 2013b. Is the history of science essentially Whiggish? Hist Sci 51/170: 85-99.

Bajos N., et al. 2003. Contraception: From accessibility to efficiency. Hum Reprod 18/5: 994-999.

Bankole A, Singh S, Haas T. 1998. Reasons why women have induced abortions: Evidence from 27 countries. Int Fam Plan Perspec 24/3: 117-127.

Berer M. 2000. Making abortions safe: A matter of good public health policy and practice. B World Health Organ 78/5: 580-592.

Blank RM, George ChC, London RA. 1996. State abortion rates: The impact of policies, providers, politics, demographics, and economic environment. $J$ Health Econ 15: 513-553.

Boongaarts J, Westoff ChF. 2000. The potential role of contraception in reducing abortion. Stud Family Plann 31/3: 193-202.

Brody BA. 1971. Abortion and the law. J Philos 68/12: 357-369.

Finer LB, Henshaw SK. 2006. Disparities in rates of unintended pregnancies in the United States, 1994 and 2001. Perspect Sex Repro H 38/2: 90-96.

Finer LB, Zolna MR. 2011. Unintended pregnancy in the United States: Incidence and disparities 2006. Contraception 84: 478-485. 
Forrest JD. 1994. Preventing unintended pregnancy: The role of hormonal contraceptives. Am J Obste Gynecol 170/5: 1485-1489.

Giubilini A, Minerva F. 2011. After-birth abortion: why should the baby live. J Med Ethics 39/5: 261-63.

Kreimer SF. 1992. The law of choice and choice of law: Abortion, the right to travel, and extraterritorial regulation in American federalism. New York $U$ Law Rev 67/3: 451419.

Marston C, Cleland J. 2003. Relationships between contraception and abortion: A review of the evidence. Int Fam Plan Perspec 29: 6-13.

May CS. 2005. Principled compromise and the abortion controversy. Roy I Ph S, 33/4: 317-348.

Meier KJ et al. 1996. The impact of state-level restrictions to abortion. Demography 33/3: 307-312.

Rahman A, Katzive L, Henshaw SK 1998. A global review of laws on induced abortion 1985-1997. Int Fam Plan Perspec 24/2: 56-64.

Sedg G et al. 2012. Induced abortion: Incidence and trends worldwide from 1995 to 2008. Lancet, 379/9816: 625-32.

Singh S, Sedgh G, Hussain R. 2010. Unintended pregnancy: Worldwide levels, trends, and outcomes. Stud Family Plann 41/4: 241-250.

Singh S et al. 2009. Adding it up: The costs and benefits of investing in family planning and maternal and newborn health. Guttmacher Institute and United Nations Population Fund :New York and Washington DC.

Trussell J. 2006. The cost of unintended pregnancy in the United States. Contraception, $5: 168-170$. 
Vincent ML, Clearie AF, Schluchter MD. 1987. Reducing adolescent pregnancy through school and community-based education. J Amer Med Assoc 257/24:3382-3386. World Health Organization. 2011. Unsafe abortion. Global and regional estimates of the incidence of unsafe abortions and associated mortality in 2008. World Health Organization. 